\title{
An Overview of Current Tax Incentives Matters Among Companies in Malaysia
}

\author{
Low Mei Peng, Chung Chay Yoke, Tee Peck Ling, Shamini Kandasamy, Ung Leng Yean \\ Universiti Tunku Abdul Rahman, Malaysia \\ lowmp@utar.edu.my \\ DOI: https://doi.org/10.37134/jcit.vol9.1.2019
}

\begin{abstract}
The Earth is sick! The fact of climate change is now widely accepted by every major scientific body universally. The environment is positing challenges to everyone. People around the world have taken notice of the world's ills, and major governments are working on solutions to curb with the pressing issues to slow down the effects and begin to shape a better world for the future. Some of the initiatives by the Malaysian Government is the introduction of tax incentives among the companies. This study aims to provide an overview of the current tax incentive issues among companies in Malaysia. Purposive sampling method was adopted to collect responses from Malaysian companies by using a semi-structured questionnaire. The results reveal that majority of the companies acknowledged the predicament of rising production cost and emerging environmental issues yet most of them are unaware about the tax incentives offered by the Government. The study informed that the facilitating factors for tax incentives application and implementation are the companies' financial resources; supportive management, and the clear directives from the Government. Time consuming in studying the requirement, complicated procedures and benefit reap from the tax incentives application are the main barriers that contribute to low tax incentive applications. This study contributes by providing a timely review of current tax incentives situations in Malaysia and proposals for better utilisation of tax incentives for companies' performance.
\end{abstract}

Keywords: Tax incentives; Types of tax incentives; Awareness; Malaysian companies

\section{Background of The Study}

Millions of ringgits has been spent by the Government on storage and disposal costs due to irresponsible businesses making Malaysia their dumping ground for their unwanted industrial waste. Port Klang Authority (PKA) general manager Capt. Mr. K. Subramaniam said that some of these plastic waste contaminated chemicals potentially threaten the environment if left there without proper treatment for too long period (The Star Online, 2017). However, proper handling of industrial waste seems to contradict with bottom-line of businesses since businesses in Malaysia have been experiencing rising production costs during a period of economic slowdown. According to Malaysian Institute of Economic Research (MIER), forecast of Malaysia exports for 2017 would be reduced from 3\% to 1.3\% and the Gross Domestic Product (GDP) growth is also expected to be stagnant at $4.6 \%$ (MIER, 2017). Therefore, companies in Malaysia are urged to consider switching to renewable resources as a means to cope with rising costs and also to keep pace with greener and sustainable environmental development.

\section{Introduction}

Malaysian Government acknowledges the importance of sustainable environment and taken numerous measures to achieve it. Among others is the offers of tax incentives in the form of 
tax deductions for costs such as Assessment Fee, Annual Fee and others Fee imposed by Standards Malaysia. Malaysian Investment Development Authority (MIDA) has initiated some incentives for storage, treatment and disposal of toxic and hazardous waste as well as waste recycling activities. Regrettably, there are still very low numbers of companies utilising these investment tax incentives and engaged in environmental protection activities (Sakarnor et al, 2009). According to a study by Mao and Wang (2016) in China, both of the environmental tax incentives such as investment tax credit and taxable income deduction provided since year 2008 to firms engage in business activities related to reducing pollution emissions and energy savings are generally under-utilised. As such, there is no significant changes been made among firms in China on environmental behaviour despite the availability of tax incentives offered. The phenomena highlight the issues of low awareness, under-utilization and ineffective of policy.

In view of the under-utilization of environmental tax incentives, it poses some research problems to be resolved. Firstly, this study aims to find out the awareness of Malaysian firms and corporations of various types of environmental tax incentives provided by the Government. Secondly, this study looks into all types of tax incentives such as Tax Incentive for Green Technology Project Tax Incentive for Green Technology Services and Tax Incentive for Purchase of Green Technology Assets (MIDA, 2017) concurrently. As there is little literature in Malaysia on the incentives, the findings allow ranking these types of tax incentives and comparing them as to which are relatively more popular among Malaysian companies. Besides this, since there are yet to have any firm-level study in Malaysia that look into the key factors that can successfully lead to improvement in environmental behaviour of Malaysian businesses, this proposed research will be able to provide some new empirical evidence to close the research gap of why environmental tax incentives are still under-utilised in Malaysia as reported by MIDA (2017). Findings from this study could provide significant implications for the Government policymakers and tax authority.

Addressing this research gap in the present situation, this study comes with the following objectives; To assess whether companies in Malaysia are aware of tax incentives which offer savings that they could enjoy if they are environmental friendly in their business operations; To examine which type of tax incentives are most popular among the companies and also effectively changing the environmental behaviour of Malaysian businesses; To find out the factors that can successfully lead to improvement of environmental behaviour and take full advantage of the associated tax benefits provided among Malaysian businesses; and To identify some shortcomings of the current environmental tax incentives system in Malaysia. To address these research objectives, the rest of the paper proceeds as follow: We first present the study of past literature review on tax incentives. Next, we look into the types of incentives currently offered by Malaysian Government to companies before presenting the research design and research methodology undertake to carry out the research. The description of the findings shed light on the current tax incentives awareness among the companies and the most effective type of incentives along with the factors that encourage and discourage their tax incentives application. In doing so, proposal to solve the discouraging factors are presented before ending with conclusion. 


\section{Literature Review}

In China, a unit set up to oversee environmental protection was taken to Ministerial level. This was an achievement to have a framework to achieve a sustainable development. Besides having incentives, China has also adopted several penalties for companies not adhering to the rules when companies pollute the environment (Cheng \& Shi, 2015).

By giving tax incentives companies can take advantage of this to improve green technology. Pollution taxes and direct regulations are an encouragement for environment policies. There also must be a body of enforcement that is effective to monitor the companies Oates and Baumol (1975, p. 103 and p. 106). There must be a monitoring system to ensure the effectiveness of companies that are taking advantage of the incentives.

The possibility of United States manufacturing companies moving into Mexico because of the North American Free Trade Agreement, but the Government suggested different pollutant tax incentives that the companies took advantage. Tax incentives were a main driver for companies in the United States (Yang \& Mai, 2013)

Hwang and Mai (2004) explained that if a pollution standard is not related to the plant location, incentives will make the companies to relocate where there are incentives. Hence, it proves that companies are willing to take the incentives only if they are aware about it.

In the United States, there are several tax incentives that companies fail to take advantage of and causing companies to pay higher taxes. It is the ignorance of the companies and they have realised that is not an excuse (Reynoso, \& Heusinger, 2010).

There are a number of reliefs being offered for companies and small and medium sized companies. These incentives must be closely monitored for companies to take advantage of the incentives. Without the support of the Governing, the companies will have to seek advice and make sure the incentives are being used De Gouveia (K. N, 2014).

\section{Types of Tax Incentives}

The tax incentives offered by the Malaysian Government come with manifolds based on the specific industry needs and wide in its application based on industries and businesses. These tax incentives are also constantly change and update or withdraw subject to meet the challenges and needs of the Malaysian economy. Currently, MIDA offers the following type of tax incentive:

\section{Green Technology Incentive}

Green Technology incentives includes added qualifying activities. These incentives are in the form of investment tax allowances for the purchase of green technology assets and the income tax exemption will be given for the use of green technology services and system. These incentives will cover a broad number of green technology activities relating to renewable energy and energy efficiency projects. 


\section{Tax Incentive for Green Technology Project}

Investment Tax Allowance (ITA) of 100\% qualifying capital expenditure incurred on the green technology from 2013 until 2020 can be offset by 70\% of statutory income in the year of assessment. Any unutilised allowances can be carried forward until it is fully absorbed, which is an attractive incentive to businesses. Green technology projects related to renewable energy, energy efficiency, green building, green data centre and waste management qualifies for the incentives.

\section{Tax Incentive for Green Technology Services}

Green technology services related to renewable energy, energy efficiency, electric vehicle $(\mathrm{EV})$, green building, green data centre, green certification and verification, and green township can qualify for this tax incentive. This income tax incentive of $100 \%$ of statutory income from the year of assessment of 2013 to 2020.

\section{Tax Incentive for Purchase of Green Technology Assets}

Investment Tax Allowance (ITA) of 100\% of qualifying capital expenditure incurred on green technology asset from the year of assessment 2013 until the year of assessment 2020. The allowance can be offset against $70 \%$ of statutory income in the year of assessment. Unutilised allowances can be carried forward until they are fully absorbed. The purchase of green technology assets as listed in MyHijau Directory can qualify for this tax incentive. This tax incentive is targeting toward industries and businesses that involve in procumbent and purchase of energy saving equipment and plants.

\section{Research Design and Research Methodology}

This primary objective of this study is to explore and understand the tax incentive awareness along with the facilitating factors for its application among companies in Malaysia. Hence, a semi-structured questionnaire was used as a tool to collect responses from the targeted respondents. The semi-structured interview guide provides a clear set of instructions for interviewers and can provide reliable, comparable qualitative data. This feature meets the current study objectives. In fact, semi-structured interviews are often preceded by observation, informal and unstructured interviewing in order to allow the researchers to develop a keen understanding of the topic of interest. The inclusion of open-ended questions follow relevant topics offer the opportunity for identifying new approaches of seeing and understanding the topic at hand. As such, semi-structured interview was adopted.

The semi-structured questionnaire comes in five sections. Section A consists of items to capture the companies' characteristics which is measured in categorical data. Section B is made up of items that measure the level of firm's awareness or claim on various types of tax incentive rendered by the Government. Section $C$ includes items that measure the extent of firm's environmental friendliness in its business operations. Section D consists of items quantify various factors that lead to implementation and improvement of environmental behaviour by the firm. Items in Sections B, C and D are measured in 7-point Likert scale. 
Section E provides an avenue for respondents to feedback on the current study topic and their opinions on current tax incentives matter in Malaysia from their business perspectives.

Purposive sampling method was used to identify the targeted respondents. The targeted sample companies are selected from SME Directory and corporations from obtained public listed database accordance to their sector categorization. Firstly, the researchers identify the companies based on the directory and database before contacting the companies for their agreement and willingness to participate in this study. Among 120 companies contacted, only 26 companies responded and agreed to participate.

Quantitative responses obtained from the survey was then analysed by providing descriptive statistics on the companies' characteristics, their awareness of tax incentives, type of tax incentives applied and planning to apply and factors in facilitating application.

\section{Results and Findings}

Among the 120 companies covering Small Medium-Sized Enterprises (SMEs) and corporations, only 26 companies agreed to participate in this study, yielding a response rate of $20 \%$. For most the companies contacted and refused to participate gave common reasons as they are not aware of the tax incentives matter, hence would not be able to contribute. Meanwhile, other reasons provided are there is no personnel in charged for tax matter and they do not want to participate in this study.

The survey results reveal that $50 \%$ of the respondents have been with the companies for more than 20 years and 35\% of them for more than 10 years. Only 15\% of the respondents have been with the companies for less than 10 years. This shows that most of the respondents are familiar and experiences with the company's business processes.

Most of the companies participated in this survey are from manufacturing sector which account for $20 \%$ of the responses and followed by $12 \%$ from Electrical and Electronic related companies, $8 \%$ respectively for Wood and wood product, Construction, Rubber products, Distributive trade, $4 \%$ each for Metal product, Machinery and Engineering, Logistic, Textile and apparel. In other words, majority of the companies are in the manufacturing sector and its' relevance which tax incentive is applicable to them.

In terms of the firm size, $54 \%$ of the companies responded have more than 5 employees and less than 75 employees, i.e., medium-sized companies. The second large group of respondents are from the large companies with more than 75 employees which accounts for $38 \%$ of responses. Only $8 \%$ of the responses came from micro-sized companies with less than 5 employees. 


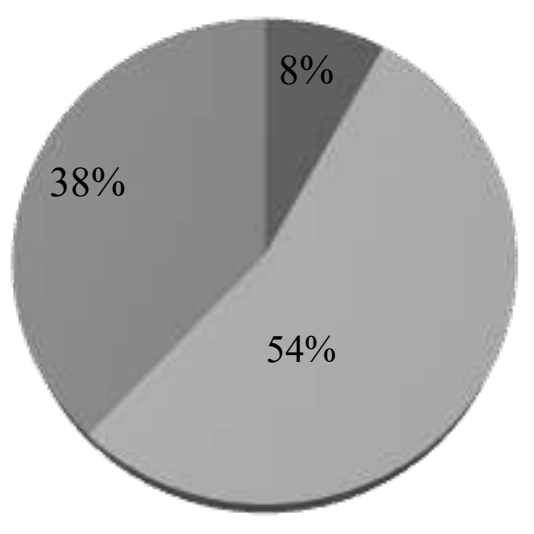

$$
\square<\text { employees } \square-75 \text { employees } \square 75-200 \text { employee }
$$

Figure 1: Size of companies participated in survey

It was surprised to uncover that $65.4 \%$ of the respondents are not aware of the tax incentives and opportunities. For the reminder $34.6 \%$; they informed that they learn about tax incentives through newspapers, $26.9 \%$ and Government published budget, $15.4 \%$. Other sources such as Business association and Internet sources only accounts for $11.0 \%$. The survey finding also reveals that $88.5 \%$ of the respondents are not aware about the procedures and documents requirement for tax incentive application. This findings alarm the authority on the issue in communicating the availability and the procedures for tax incentives application.

\section{Awareness of Tax Incentives?}

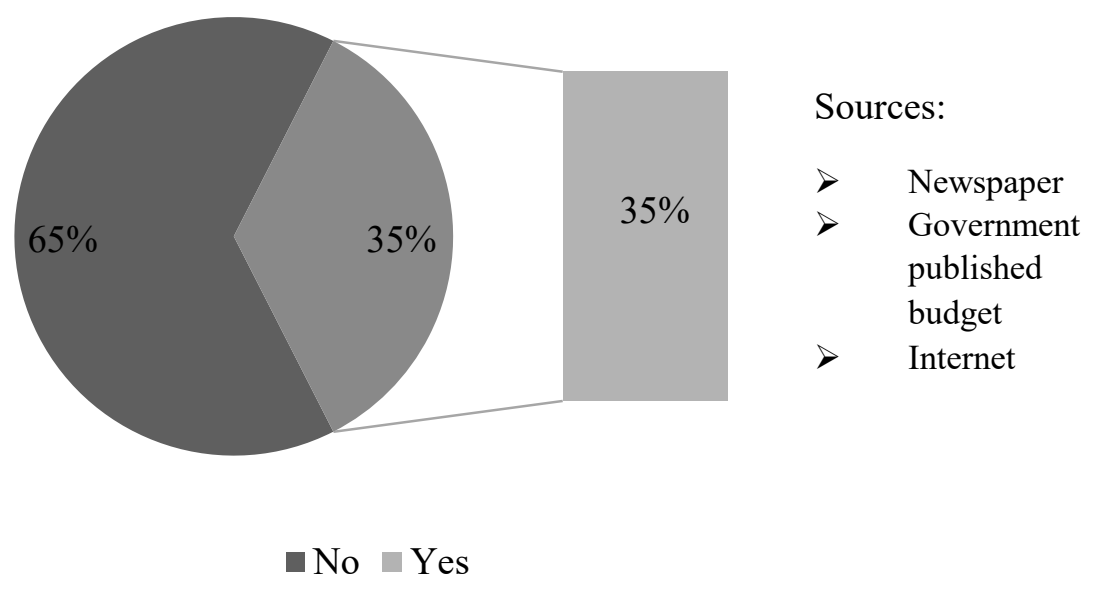

Figure 2: Awareness of Tax Incentives

In terms of the types of tax incentives that companies have applied for are Green Building, Green Sustainable Energy, such as Solar Energy and Certified emission reduction units. Green Building whereby owners of buildings are awarded with Green Building Index certificates. These certificates enabled the owner for a tax exemption of $100 \%$ of the additional capital expenditure and exemption from stamp duties, especially the first owners. 
Companies which are manufacturing based applied commonly for Green Sustainable Energy and Certified emission reduction units. This Certified emission reduction unit incentives were applicable in the year of assessment from 2008 to 2012.

When respondents were being asked on the type of tax incentives that their companies plan to apply in the near future, it was told that $23 \%$ of them do not plan to apply any tax incentives for this scheme. Meanwhile, for those companies which put tax incentives application for their future plans, they are planning to apply for Certified emission reduction unit incentives and Investment Tax Allowance (ITA). The rationale for such findings is owing to the nature of Certified emission reduction unit and ITA. ITA was introduced in conjunction with MyHijau project. ITA of $100 \%$ of qualifying capital expenditure incurred on a green technology project from the year of assessment 2013 until the year of assessment 2020. The allowance can be offset against $70 \%$ of statutory income in the year of assessment. Unutilised allowances can be carried forward until they are fully absorbed. This is a very attractive incentive to companies. The purchase of green technology assets as listed in MyHijau Directory can qualify for this tax incentive.

Majority of the respondents agreed that tax incentives would help the company's functional areas to be more environmental friendly with less energy consumption and less pollution. The results reveal that $42 \%$ in Production/ Manufacturing, followed by Administration and Logistic.

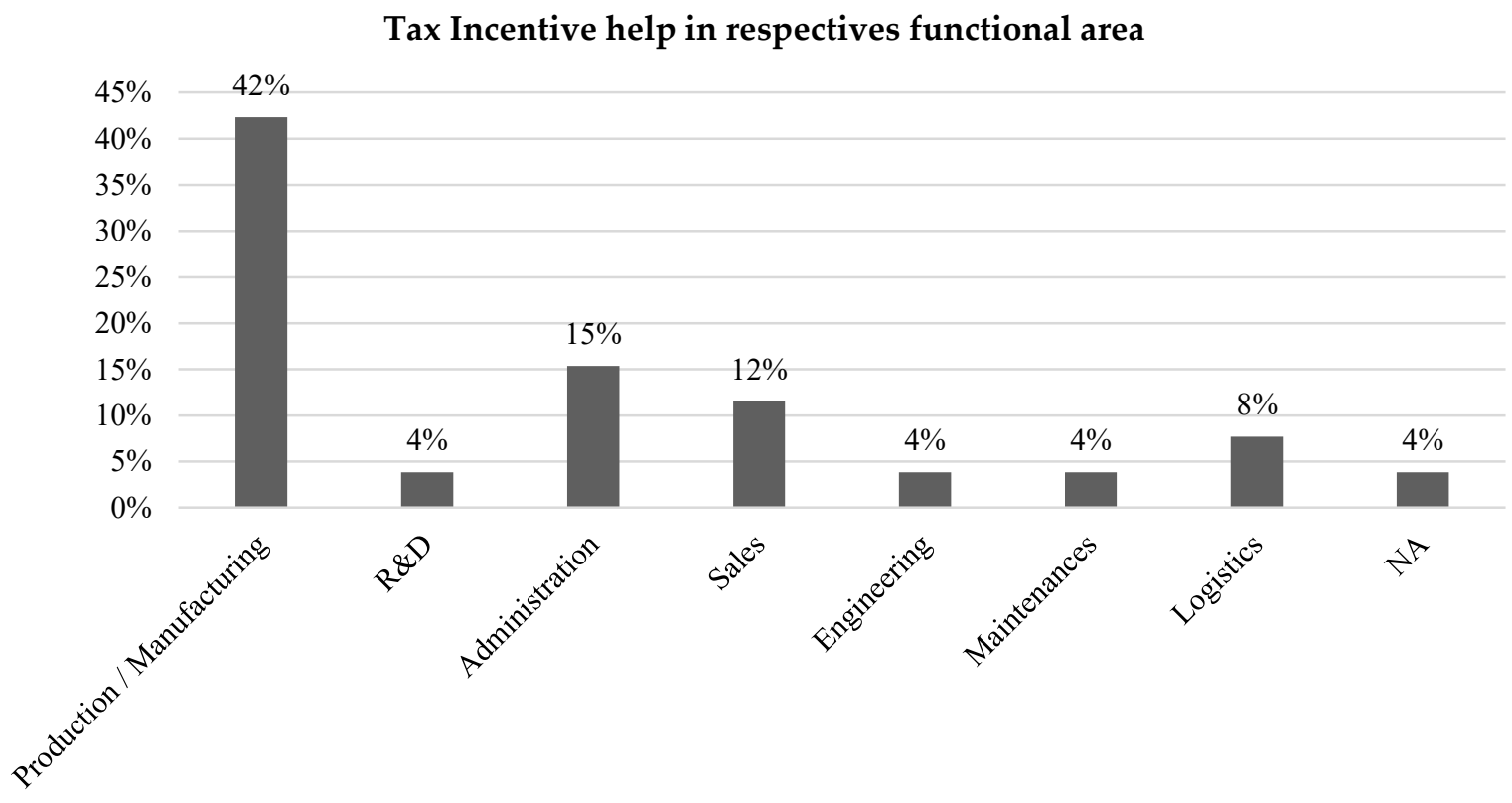

Figure 3: Tax Incentives in Firm's Functional Area

Despite the agreement on the benefits of tax incentives, about $20 \%$ of the responses informed that their companies' level of activity is still at the less active stage and therefore, they are not actively taking advantage of the business incentives arise from tax credits.

The survey also identified important factors that encourage companies in applying for tax incentives. The results reveal that the most important factor is the financial resources of the companies, followed by supportive management, infrastructure and facilities in the 
companies, organisation culture and lastly government directives. The results indicate that it is the internal factors that encourage the application of tax incentives instead of external factor such as clear government directives. In relation to this, respondents were asked to identify the primary barriers for tax incentives. Most of the responses informed that the companies are too busy in executing requirements needed in the tax incentives applications as well as too much paperwork involved. Among others, it was reported that $19 \%$ of the companies are not entitled for tax incentives due to not meeting the criteria set forth for the applications. Besides, the respondents who are aware and applied for tax incentives, feedback that the tax professionals have an important role to play. The tax professionals are expected to be able to provide practical and effective tax planning ideas to the businesses and help companies to discover and take advantage of tax incentives. In addition to the well-informed and have current knowledge of the law in various industry and various tax incentives, a committed tax agent is equally important. With the technical supports from tax professional along with the contributing factors, it is believed that tax incentive opportunities offered by Government could assist businesses to fulfil their strategic business objectives.

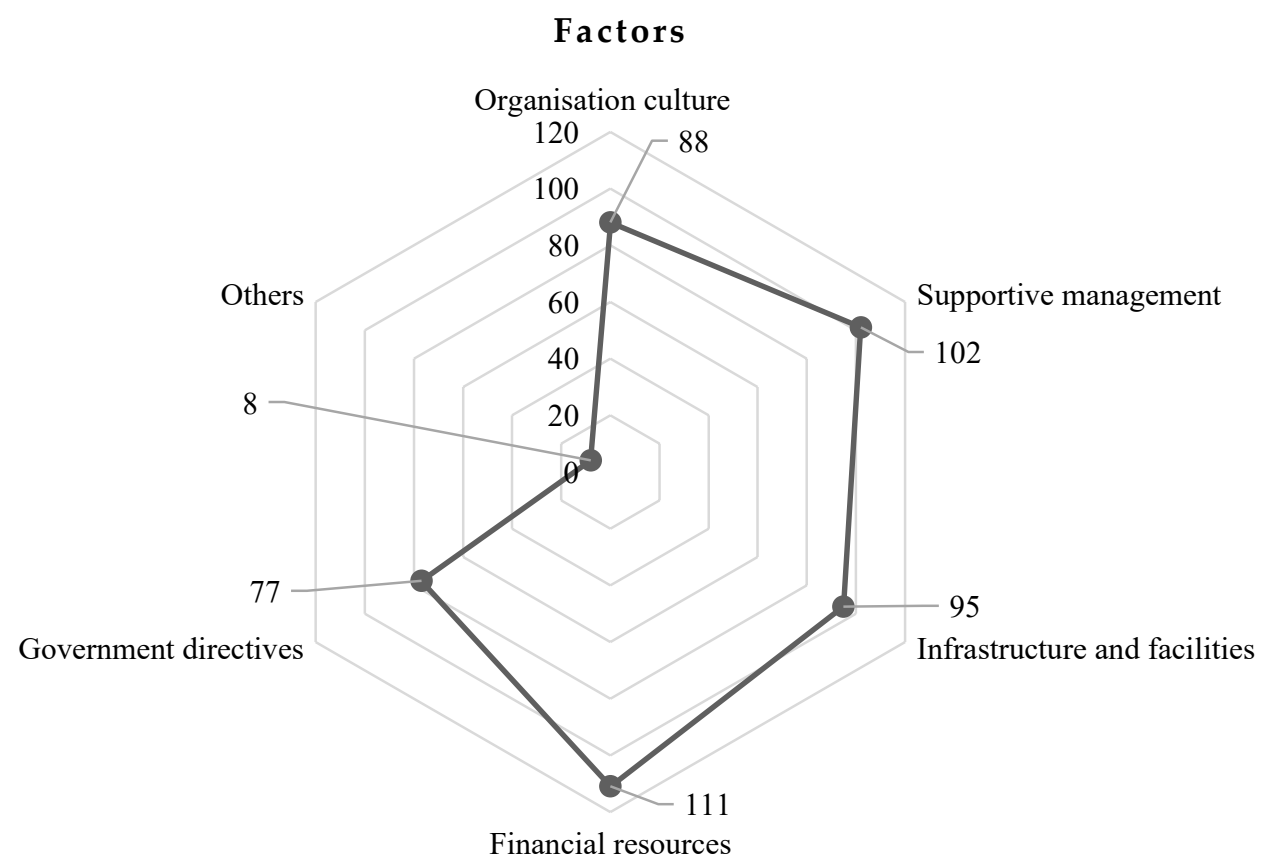

Figure 4: Contributing Factors for Tax Incentives Applications 


\section{Barriers of Tax Incentive Applications}

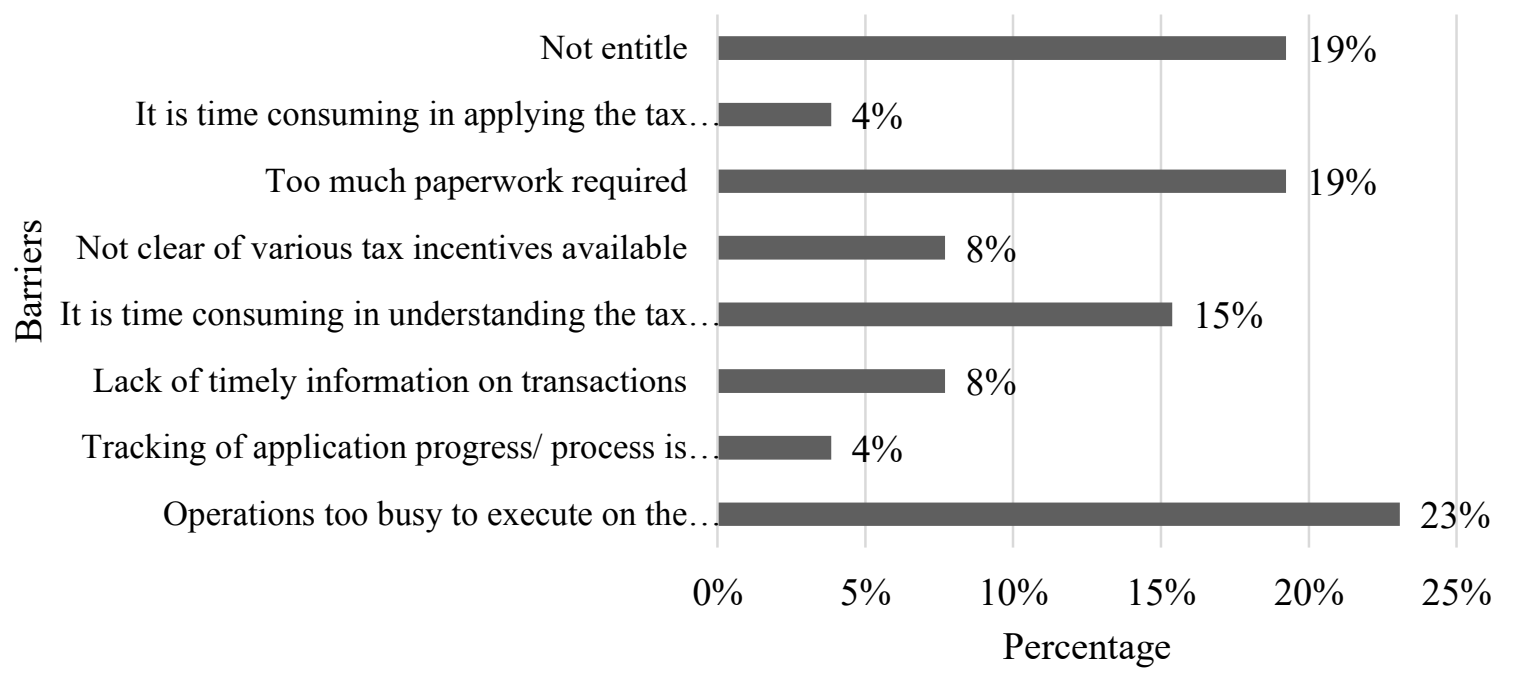

Figure 5: Barriers of Tax Incentives Applications

Respondents are in the opinion that Government has a main role to play in the tax incentives issues. Most of the respondents suggested that the Government should provide information centre and helpdesk in assisting companies in tax incentives understanding and applications. Some of the respondents proposed that the process would be more efficient with less requirement and back end administrative compliance. With that, they recommended to develop more streamlined application process and simple application procedures.

\section{Recommendations}

Majority (59.1\%) of the Malaysian SMEs and corporations interviewed revealed that they are not aware of tax incentives they could potentially enjoy if they are environmentally friendly in conducting their business operations. Due to the lack of awareness, most $(72.1 \%)$ of the Malaysian businesses also responded that they did not apply for it and thereby their level of activity to claim such incentives remain unchanged over the past two years. To create the awareness, government authorities such as Lembaga Hasil Dalam Negeri (LHDN), Malaysian Investment Development Authority (Mida), and Malaysian Green Technology Corp (GreenTech Malaysia) and SME Corp should organise more seminars and roadshows during trade expos and other business-related events at major business centres and industrial parks throughout the country. Trade and business associations should also take a more active role in sharing with their respective member firms in regard to environmental tax benefits and encourage them to claim those tax benefits. Media such as newspapers and trade journals should report on the availability of environmental tax incentives and the updated statistics of businesses claiming these incentives on a more regular basis periodically. This will not only improve the level of awareness among Malaysian businesses, but also enable them to benchmark against their peers or competitors in the same industry sector. 
In addition, with organisational culture and unsupportive management being among the least encouraging factors for Malaysian businesses to apply for environmental tax incentives, Malaysian government should consider making it mandatory for businesses to comply with certain environmental requirements and reward them with tax credits for satisfactory compliance. Asian businessmen are found to be more reluctant to change their ways of running their operations and prefer to stay in their comfort zone if compared to Western counterparts.

For $9.1 \%$ businesses that reported that there are too much administrative and paperwork required for applying and securing environmental tax incentives, government should find the best possible way to streamline the application procedures. Furthermore, for $4.5 \%$ businesses that mentioned that it is too time consuming and difficult to understand all relevant types of environmental tax incentives available, government should set up information centres and help desks to provide the right guidance and advice to businesses. There should be a low or even near to zero waiting time when businesses approach these information centres and help desks.

Due to economy slowdown and uncertain global economic outlook aftermath of US-China trade war, $18.1 \%$ of the Malaysian businesses revealed that they are in loss or unstable profit position which means exhaustion of taxable profit to claim environmental tax credits. Therefore, government should implement the right economic policies that help to bring higher growth rate in GDP and hence business activity. Only when Malaysian businesses start to generate stable and sustainable profits, their management will then be more willing to commit more financial resources to raise the level of environmental friendliness in their business operations, and subsequently claim for the associated tax incentives.

\section{References}

Cheng, S., \& Shi, S. (2015). Green Tax in the People's Republic of China. Int'1 Tax J., 41, 61.

De Gouveia, K. N. (2014). Income tax incentives for renewable energy research and development and implementation: a comparison between South Africa and China (Doctoral dissertation, University of Pretoria).

Hwang, H., \& Mai, C. C. (2004). The effects of pollution taxes on urban areas with an endogenous plant location. Environ Resource Econ 29:57-65

Malaysian Investment Development Authority MIDA (2017, August 10th). Retrieved from http://www.mida.gov.my/home/search/?find=tax+incentives

Mao, J., \& Wang, C. (2016). Tax incentives and environmental protection: Evidence from China's taxpayer-level data. China Finance and Economics Review, 4(14). Retrieved August 18, 2017, from https://chinafinanceandeconomicreview.springeropen.com/articles/10.1186/s40589-016-0040-0

MIDA. (2017). Environmental Management. Retrieved August 15, 2017, from http://www.mida.gov.my/home/environmental-management/posts/

MIER. (2017) Malaysian Economic Outlook. Retrieved August 15, 2017, from https://www.mier.org.my/

Ministry of Energy, Green Technology and Water. (2011). “Low Carbon Cities Framework and Assessment System", Retrieved August 23, 2017, from http://esci-ksp.org/wp/wpcontent/uploads/2012/04/Low-CarbonCities-Framework-and-Assessment-System.pdf

Oates, W. E., Baumol, W. J. (1975). The instruments for environmental policy. In: Mills E (ed) Economic analysis of environmental problems. Columbia University Press, New York, pp 95-128

Reynoso, R., \& Heusinger, S. (2010). Sates Offer Rich Incentives for Going Green: Is Your Company Leaving Money on the Table with Unrealized Credits and Incentives. CPA Prac. Mgmt. F., 6, 12.

Sakarnor, M., Sharifah, B., Norkhazimah, A., \& Bakhtiar, A. (2009). The awareness and utilisation of Tax Investment incentives on environmental protection activities, Energy and Environment, 3rd International Conference on 7th-8th December 2009. 
Journal of Contemporary Issues and Thought

ISSN 0128-0481/ e-ISSN 2232-0032 / Vol 9, 2019 (1-11)

The Star Online. (2017). Retrieved from http://www.thestar.com.my/news/nation/2017/06/28/port-klang-used-asdumping-ground-unwanted-waste-in-containers-shipped-in-and-discarded-byirrespons/\#LAAueQZV8YFk7FTf.99

Yang, B. S., \& Mai, C. C. (2013). The impact of uncertain environmental regulatory policy on optimal plant location and anti-pollution technology selection. The Annals of Regional Science, 50(3), 753-769. 